\title{
Oral and sublingual immunotherapy for food allergy: current progress and future directions
}

\author{
Timothy P Moran ${ }^{1}$, Brian P Vickery ${ }^{2}$, and A Wesley Burks ${ }^{2}$ \\ ${ }^{1}$ Department of Pediatrics, Division of Allergy and Immunology, Duke University Medical Center, \\ Durham, NC 27710, United States \\ ${ }^{2}$ Department of Pediatrics, University of North Carolina School of Medicine, Chapel Hill, NC \\ 27599, United States
}

\begin{abstract}
Food allergies are increasing in prevalence and present an emerging epidemic for westernized countries. Strict dietary avoidance is the only approved management for food allergy, but accidental exposures regularly occur, leading to significant patient anxiety and decreased quality of life. Over the past decade, oral and sublingual immunotherapies have emerged as potential treatments for food allergy. While several small clinical trials have demonstrated that immunotherapy can desensitize food-allergic individuals, strategies for further enhancing safety and definitively establishing long-term efficacy are needed. This review presents an overview of recent oral and sublingual immunotherapy trials, and provides a glimpse into what the next generation of food immunotherapy may entail.
\end{abstract}

\section{Introduction}

Food allergy (FA) is a serious disorder that has life-altering implications for afflicted individuals and their families. Although FA can encompass several different disease entities, here we use the term to denote an immunoglobulin $\mathrm{E}$ (IgE)-mediated hypersensitivity reaction that occurs after consuming a specific food [1]. FA affects up to $10 \%$ of the population with the highest rates in children [2-4], and incidence appears to be increasing along with other atopic disorders [3,5]. Clearly FA is a growing healthcare concern, yet effective treatment other than strict dietary avoidance remains elusive [1]. Over the past decade, several small clinical studies of two different therapeutic approaches, oral immunotherapy (OIT) and sublingual immunotherapy (SLIT), have shown promising results. In this review, we discuss recent findings of randomized controlled trials (RCT) evaluating the efficacy and safety of OIT and SLIT, and then present potential strategies for improving food immunotherapy.

\section{Immunotherapy trials for FA}

Immunotherapy involves manipulating the immune response directed against an antigen. Subjects who tolerate and successfully complete food immunotherapy protocols can experience two possible outcomes. The first is desensitization, where continuous allergen exposure increases the threshold of clinical reactivity to the food. The second and more ideal outcome is clinical tolerance, which is defined as the ability to consume a food without allergic symptoms after treatment is ceased indefinitely. It is unknown whether 'tolerance'

\footnotetext{
(C) 2013 Elsevier Ltd. All rights reserved.

Corresponding author: Burks, A Wesley (wburks@email.unc.edu).
} 
after immunotherapy resembles the natural tolerance that occurs spontaneously for some FA patients, or if therapeutic tolerance is mechanistically similar to classical immune tolerance. For this reason, the term 'sustained unresponsiveness' has been introduced into the literature to avoid confusion [6••]. How such a change develops in humans is incompletely understood, but possibly involves the generation of allergen-specific regulatory $\mathrm{T}$ cells (Treg) or deletion of effector T cells [7,8]. Other immunological changes described in desensitized patients include decreased allergen-specific IgE but increased specific IgG4, and diminished mast cell and basophil activity $[6,9,10,11 \bullet, 12 \bullet]$.

OIT

OIT comprises the daily consumption of milligrams to grams of allergen, typically mixed with a food vehicle, which is incrementally increased over weeks to months with the goal of inducing desensitization and ultimately tolerance. Open-label pilot studies involving patients with milk, egg, and peanut allergies had suggested that OIT could increase the threshold of clinical reactivity to the culprit food [10,13-15]. Recent RCT have provided further compelling evidence that OIT can frequently induce desensitization in patients with FA $[6,9,12 \bullet$, although the effect varies across studies (Table 1).

There is evidence that OIT can also result in clinical tolerance or sustained unresponsiveness. In 2012, Keet et al. reported that $40 \%$ of subjects receiving milk OIT passed an OFC when treatment was ceased for 6 weeks [16•], although it is possible that some may have naturally outgrown their FA. That same year, a study by the Consortium for FA Research (CoFAR) found that of 30 patients desensitized with egg OIT, eleven $(27.5 \%$ of the active treatment group) passed on OFC after halting therapy for 4-6 weeks [6••]. These individuals continued to consume egg regularly without problems when surveyed 12 months later. The likelihood of spontaneous FA resolution was very low in this study, and none of the control subjects exhibited evidence of outgrowing their egg sensitivity. This landmark article was the first to suggest that OIT could be a truly disease-modifying treatment.

\section{SLIT}

SLIT involves placement of micrograms to milligrams of allergen under the tongue with doses that are up to 1000-fold less than OIT. A few RCT have investigated allergen-specific SLIT for patients with milk [16•], peanut [11•,17•], hazelnut [18] and peach allergies [19], demonstrating varying degrees of efficacy (Table 1). One of the most informative studies to date was a CoFAR-sponsored multicenter RCT for peanut SLIT involving forty subjects.

After 44 weeks of therapy, $70 \%$ of patients receiving SLIT developed partial desensitization to peanut, compared to only $15 \%$ of the placebo group $(P<0.001)$. These findings were slightly inferior to a prior single center study of peanut SLIT [11•], indicating the importance of performing multicenter trials to more accurately assess treatment effect.

One randomized study attempted to directly compare the efficacy of OIT and SLIT for the treatment of cow's milk allergy [16•]. After an initial dose escalation with SLIT, 30 subjects were randomized to continue either daily SLIT or begin OIT at two different maintenance doses. Sixty weeks later, $70 \%$ of subjects in the OIT group passed a milk OFC, compared to only $10 \%$ in the SLIT group. The apparent superior efficacy of OIT was mitigated by a higher rate of systemic reactions during therapy. A retrospective comparison study of peanut-allergic individuals treated with either peanut OIT or SLIT also found greater efficacy associated with the former [20]. Thus, OIT may prove to be more efficacious than SLIT, but this could come at the expense of safety. 


\section{Summary of clinical trials}

Some general conclusions can be drawn from the few published RCT for OIT and SLIT. First, a very small number of individuals have been subjected to rigorous study, thus restricting the generalizability of reported findings. Of those treated with OIT, greater than $80 \%$ experience at least partial desensitization to the food allergen while on therapy. Complete desensitization, which can be conservatively defined as passing a $5 \mathrm{~g}$ OFC without symptoms [21], occurs in $45-75 \%$ of OIT subjects. The rate is even lower for SLIT, with few subjects reaching full desensitization during the blinded phases of the trials. Only a minority of OIT subjects (25-40\%) develops a state that resembles clinical tolerance; thus, prolonged and potentially indefinite therapy may be needed to provide adequate protection for most patients. The safety profile of OIT and SLIT is also less than ideal. Treatmentrelated adverse events are relatively frequent and reactions requiring epinephrine appear to occur more often when compared to the practice of dietary avoidance [22]. There have also been isolated reports of new eosinophilic gastrointestinal disorders developing in individuals receiving OIT [23]. Lastly, nearly all studies have excluded patients with severe foodinduced anaphylaxis, which is the population in most need of effective interventions. Given these limitations, it is not surprising that two recent Cochrane reviews of OIT for milk [24•] and peanut [25] allergies found insufficient evidence to support its clinical implementation, which is in accordance with current clinical guidelines [1]. With the many uncertainties surrounding the long-termefficacy and safety of OIT and SLIT, we share the opinion of other leading researchers that food immunotherapy remains in a state of clinical equipoise $[26 \bullet]$.

\section{Strategies for enhancing food immunotherapy}

OIT and SLIT are promising treatments for FA, but it is unlikely that current protocols will be effective for all patients, especially those with a more severe phenotype. The next generation of food immunotherapy should seek to further increase the likelihood of developing long-term tolerance while minimizing adverse events associated with treatment. Three general strategies for improving immunotherapy include firstly modifying the immunological characteristics of the food allergen, secondly adjunct treatment with immunomodulatory agents, and lastly utilizing alternative antigen delivery schemes (Figure 1). A variety of interventions that address these areas have been proposed, many of which are already being tested in the clinical setting.

\section{Modification of food allergens}

Altering the molecular structure of food allergens to decrease their allergenicity, while maintaining their immunotherapeutic effect, is an attractive approach for improving the safety of immunotherapy. Extensive heating is a straightforward method for changing the allergenicity of some foods (e.g. milk and eggs), as it results in the loss of conformational epitopes recognized by IgE [27]. A large proportion of patients allergic to milk or eggs tolerate the foods in baked forms [28,29], and two recent studies suggest that routine consumption of extensively heated food allergens can accelerate allergy resolution. In the first study, milk-allergic subjects able to add baked milk to their diets were 16-fold more likely to develop complete milk tolerance compared to a matched observational cohort that avoided all milk products [30•]. Similar results were observed for egg-allergic patients who incorporated baked egg into their diets [31]. The use of heat-denatured allergens in OIT and SLIT could lead to fewer treatment-related adverse events, a notion that requires further investigation.

A more targeted approach for decreasing allergenicity is to genetically alter the immunodominant B cell epitopes. Point mutagenesis of specific amino acids within the 
major peanut allergens Ara h 1-3 substantially decreased recognition when blotted with pooled peanut-specific IgE from allergic human volunteers [32]. Treatment of peanutsensitized mice with heat-killed Escherichia coli expressing these engineered recombinant peanut allergens was protective against peanut-induced anaphylaxis [33]. On the basis of these encouraging animal studies, a phase I clinical trial was performed using rectal administration of a similar product. Unfortunately, 5 of 10 subjects had to withdraw from the study due to treatment-related adverse events [34]. Successfully engineering recombinant hypoallergenic food allergens for use in immunotherapy trials might require individualized approaches, a labor-intensive process that may limit clinical feasibility.

\section{Adjunct therapy with immunomodulatory agents}

Altering the immune environment to prevent Th2-mediated responses directed against immunotherapeutic agents is another approach for reducing adverse events during OIT and SLIT. In this regard, agents that inhibit IgE-mediated signaling pathways, such as the monoclonal antibody omalizumab, could improve the safety of food immunotherapy. AntiIgE monotherapy for peanut allergy could increase the sensitivity threshold for a subset of patients [35], but was associated with an unacceptably high rate of severe adverse reactions in a recent phase II trial [36]. Therefore, using omalizumab as an adjunct to OIT or SLIT may be a safer and more effective strategy. Accordingly, Nadeau and colleagues investigated the utility of using omalizumab to facilitate desensitization in a small group of children undergoing high-dose milk OIT [37•]. After 9 weeks of pretreatment with omalizumab, 9 of the 11 patients initially enrolled were able to rapidly reach maintenance dosing with minimal adverse events. Several small trials combining omalizumab treatment and OIT for other food allergens are currently underway (ClinicalTrials.gov, NCT01510626, NCT01157117, NCT00932282).

An herbal formulation (FAHF-2) containing nine herbs used in traditional Chinese medicine is being evaluated as a possible treatment for FA. In preclinical studies, FAHF-2 had multiple immunomodulatory effects and protected mice from peanut-induced anaphylaxis [38,39]. Subsequent phase I trials in patients with FA have shown FAHF-2 to be well tolerated with minimal side effects [40,41]. Whether FAHF-2 would have synergistic effects when combined with OIT or SLIT is currently unknown.

Other immunomodulatory strategies for improving FA immunotherapy include the use of Th1-promoting adjuvants [42], helminth therapy [43], and monoclonal antibodies directed against cytokines associated with Th2-mediated inflammation [44]. While it is possible that biological agents alone will be efficacious treatments for FA, combining them with allergenspecific immunotherapy protocols may be a more effective approach that warrants further investigation.

\section{Alternative allergen delivery strategies}

It is possible that the gut mucosa in FA patients is fundamentally altered to promote allergic responses against ingested antigens, and therefore delivering allergens to other tissues may prove more effective for generating tolerance. Accordingly, epicutaneous immunotherapy (EPIT), which involves the application of an allergen-loaded patch on intact skin, was shown to modestly desensitize milk allergic patients in a small RCT [45]. These findings have prompted further clinical inquiries into the efficacy of EPIT for the treatment of FA (ClinicalTrials.gov, NCT01170286, NCT01197053).

The use of nanoparticles for allergen delivery is a developing area that could be directly applicable to OIT and SLIT. Nanoparticles can be designed to target dendritic cells, which are important for inducing regulatory $\mathrm{T}$ cells. They can also be engineered to provide a 
sustained release of antigen, thus obviating the need for daily dosing [46]. Nanoparticles containing peanut proteins were recently generated and tested in mice, and induced a greater Th1 response than protein alone [47]. These preliminary findings will hopefully lead to more extensive studies regarding the use of nanotechnology for allergen immunotherapy.

\section{Conclusions}

The past decade has been an exciting period in the area of FA research, as studies regarding OIT and SLIT provide hope that an effective therapy for FA is within reach. Given the encouraging results from small clinical trials, it is understandable why some are advocating strongly for immediate implementation of OIT and SLIT for the treatment for FA. However, definitive evidence of safety and efficacy are lacking with the current immunotherapeutic strategies for FA, and more research is needed before these therapies can be offered to patients in routine clinical practice. The next generation of food immunotherapies will hopefully build upon the early success of OIT and SLIT, and help make an emerging treatment into the standard of care.

\section{Acknowledgments}

We thank Arlene Mendoza-Moran for proof reading and grammatical review.

\section{References and recommended reading}

Papers of particular interest, published within the period of review, have been highlighted as:

- of special interest

•• of outstanding interest

1. Boyce JA, Assa'ad A, Burks AW, Jones SM, Sampson HA, Wood RA, Plaut M, Cooper SF, Fenton MJ, Arshad SH, et al. Guidelines for the diagnosis and management of food allergy in the United States: report of the NIAID-sponsored expert panel. J Allergy Clin Immunol. 2010; 126:S1-S58. [PubMed: 21134576]

2. Chafen JJ, Newberry SJ, Riedl MA, Bravata DM, Maglione M, Suttorp MJ, Sundaram V, Paige NM, Towfigh A, Hulley BJ, et al. Diagnosing and managing common food allergies: a systematic review. JAMA. 2010; 303:1848-1856. [PubMed: 20460624]

3. Branum AM, Lukacs SL. Food allergy among children in the United States. Pediatrics. 2009; 124:1549-1555. [PubMed: 19917585]

4. Osborne NJ, Koplin JJ, Martin PE, Gurrin LC, Lowe AJ, Matheson MC, Ponsonby AL, Wake M, Tang ML, Dharmage SC, et al. Prevalence of challenge-proven IgE-mediated food allergy using population-based sampling and predetermined challenge criteria in infants. J Allergy Clin Immunol. 2011; 127:668-676. e661-e662. [PubMed: 21377036]

5. Sicherer SH, Munoz-Furlong A, Godbold JH, Sampson HA. US prevalence of self-reported peanut, tree nut, and sesame allergy: 11-year follow-up. J Allergy Clin Immunol. 2010; 125:1322-1326. [PubMed: 20462634]

6. Burks AW, Jones SM, Wood RA, Fleischer DM, Sicherer SH, Lindblad RW, Stablein D, Henning AK, Vickery BP, Liu AH, et al. Oral immunotherapy for treatment of egg allergy in children. N Engl J Med. 2012; 367:233-243. [PubMed: 22808958] This trial demonstrated that over one-quarter of egg-allergic subjects undergoing OIT remained clinically tolerant to eggs after ceasing therapy for greater than 4 weeks, strongly suggesting that immunotherapy can modify the natural course of food allergy.

7. Vickery BP, Scurlock AM, Jones SM, Burks AW. Mechanisms of immune tolerance relevant to food allergy. J Allergy Clin Immunol. 2011; 127:576-584. quiz 585-576. [PubMed: 21277624] 
8. Bedoret D, Singh AK, Shaw V, Hoyte EG, Hamilton R, DeKruyff RH, Schneider LC, Nadeau KC, Umetsu DT. Changes in antigen-specific T-cell number and function during oral desensitization in cow's milk allergy enabled with omalizumab. Mucosal Immunol. 2012; 5:267-276. [PubMed: 22318492]

9. Skripak JM, Nash SD, Rowley H, Brereton NH, Oh S, Hamilton RG, Matsui EC, Burks AW, Wood RA. A randomized, double-blind, placebo-controlled study of milk oral immunotherapy for cow's milk allergy. J Allergy Clin Immunol. 2008; 122:1154-1160. [PubMed: 18951617]

10. Jones SM, Pons L, Roberts JL, Scurlock AM, Perry TT, Kulis M, Shreffler WG, Steele P, Henry KA, Adair M, et al. Clinical efficacy and immune regulation with peanut oral immunotherapy. J Allergy Clin Immunol. 2009; 124:292-300. 300.e291-300.e297. [PubMed: 19577283]

11. Kim EH, Bird JA, Kulis M, Laubach S, Pons L, Shreffler W, Steele P, Kamilaris J, Vickery B, Burks AW. Sublingual immunotherapy for peanut allergy: clinical and immunologic evidence of desensitization. J Allergy Clin Immunol. 2011; 127:640-646. e641. [PubMed: 21281959] First randomized controlled trial demonstrating that peanut SLIT can safely induce clinical desensitization in peanut-allergic children.

12. Varshney P, Jones SM, Scurlock AM, Perry TT, Kemper A, Steele P, Hiegel A, Kamilaris J, Carlisle S, Yue X, et al. A randomized controlled study of peanut oral immunotherapy: clinical desensitization and modulation of the allergic response. J Allergy Clin Immunol. 2011; 127:654660. [PubMed: 21377034] First randomized controlled trial to show the ability of peanut OIT to clinically desensitize children with peanut allergy.

13. Meglio P, Bartone E, Plantamura M, Arabito E, Giampietro PG. A protocol for oral desensitization in children with IgE-mediated cow's milk allergy. Allergy. 2004; 59:980-987. [PubMed: 15291907]

14. Buchanan AD, Green TD, Jones SM, Scurlock AM, Christie L, Althage KA, Steele PH, Pons L, Helm RM, Lee LA, et al. Egg oral immunotherapy in nonanaphylactic children with egg allergy. $\mathbf{J}$ Allergy Clin Immunol. 2007; 119:199-205. [PubMed: 17208602]

15. Longo G, Barbi E, Berti I, Meneghetti R, Pittalis A, Ronfani L, Ventura A. Specific oral tolerance induction in children with very severe cow's milk-induced reactions. J Allergy Clin Immunol. 2008; 121:343-347. [PubMed: 18158176]

16. Keet CA, Frischmeyer-Guerrerio PA, Thyagarajan A, Schroeder JT, Hamilton RG, Boden S, Steele P, Driggers S, Burks AW, Wood RA. The safety and efficacy of sublingual and oral immunotherapy for milk allergy. J Allergy Clin Immunol. 2012; 129:448-455. 455 e441-455 e445. [PubMed: 22130425] This study found that OIT was more efficacious than SLIT for inducing desensitization in milk-allergic patients, but was associated with more severe adverse reactions during treatment.

17. Fleischer DM, Burks AW, Vickery BP, Scurlock AM, Wood RA, Jones SM, Sicherer SH, Liu AH, Stablein D, Henning AK, et al. Sublingual immunotherapy for peanut allergy: a randomized, double-blind, placebo-controlled multicenter trial. J Allergy Clin Immunol. 2013; 131:119-127. e111-e117. [PubMed: 23265698] This multicenter trial demonstrated that peanut SLIT was generally safe and partially desensitized $70 \%$ of treated subjects.

18. Enrique E, Pineda F, Malek T, Bartra J, Basagana M, Tella R, Castello JV, Alonso R, de Mateo JA, Cerda-Trias T, et al. Sublingual immunotherapy for hazelnut food allergy: a randomized, double-blind, placebo-controlled study with a standardized hazelnut extract. J Allergy Clin Immunol. 2005; 116:1073-1079. [PubMed: 16275379]

19. Fernandez-Rivas M, Garrido Fernandez S, Nadal JA, Diaz de Durana MD, Garcia BE, GonzalezMancebo E, Martin S, Barber D, Rico P, Tabar AI. Randomized double-blind, placebo-controlled trial of sublingual immunotherapy with a Pru p 3 quantified peach extract. Allergy. 2009; 64:876883. [PubMed: 19183164]

20. Chin SJ, Vickery BP, Kulis MD, Kim EH, Varshney P, Steele P, Kamilaris J, Hiegel AM, Carlisle SK, Smith PB, et al. Sublingual versus oral immunotherapy for peanut-allergic children: a retrospective comparison. J Allergy Clin Immunol. 2013; 132:476-478. [PubMed: 23534975]

21. Sampson HA, Gerth van Wijk R, Bindslev-Jensen C, Sicherer S, Teuber SS, Burks AW, Dubois AEJ, Beyer K, Eigenmann PA, Spergel JM, et al. Standardizing double-blind, placebo-controlled oral food challenges: American Academy of Allergy. Asthma \& Immunology - European 
Academy of Allergy and Clinical Immunology PRACTALL consensus report. J Allergy Clin Immunol. 2012; 130:1260-1274. [PubMed: 23195525]

22. Nguyen-Luu NU, Ben-Shoshan M, Alizadehfar R, Joseph L, Harada L, Allen M, St-Pierre Y, Clarke A. Inadvertent exposures in children with peanut allergy. Pediatr Allergy Immunol. 2012; 23:133-139. [PubMed: 22136608]

23. Sanchez-Garcia S, Rodriguez Del Rio P, Escudero C, Martinez-Gomez MJ, Ibanez MD. Possible eosinophilic esophagitis induced by milk oral immunotherapy. J Allergy Clin Immunol. 2012; 129:1155-1157. [PubMed: 22236725]

24. Yeung JP, Kloda LA, McDevitt J, Ben-Shoshan M, Alizadehfar R. Oral immunotherapy for milk allergy. Cochrane Database Syst Rev. 2012; 11:CD009542. [PubMed: 23152278] This study along with Ref [25] demonstrates that the majority of OIT trials for milk and peanut allergies are of poor quality, and there is presently insufficient evidence to support their clinical implementation.

25. Nurmatov U, Venderbosch I, Devereux G, Simons FE, Sheikh A. Allergen-specific oral immunotherapy for peanut allergy. Cochrane Database Syst Rev. 2012; 9:CD009014. [PubMed: 22972130]

26. Sampson HA. Peanut oral immunotherapy: is it ready for clinical practice? J Allergy Clin Immun. $2013 ; 1: 15-21$. Excellent brief review of the clinical readiness of peanut OIT.

27. Cooke SK, Sampson HA. Allergenic properties of ovomucoid in man. J Immunol. 1997; 159:2026-2032. [PubMed: 9257870]

28. Nowak-Wegrzyn A, Bloom KA, Sicherer SH, Shreffler WG, Noone S, Wanich N, Sampson HA. Tolerance to extensively heated milk in children with cow's milk allergy. J Allergy Clin Immunol. 2008; 122:342-347. 347 e341-347 e342. [PubMed: 18620743]

29. Lemon-Mule H, Sampson HA, Sicherer SH, Shreffler WG, Noone S, Nowak-Wegrzyn A. Immunologic changes in children with egg allergy ingesting extensively heated egg. J Allergy Clin Immunol. 2008; 122:977-983. e971. [PubMed: 18851876]

30. Kim JS, Nowak-Wegrzyn A, Sicherer SH, Noone S, Moshier EL, Sampson HA. Dietary baked milk accelerates the resolution of cow's milk allergy in children. J Allergy Clin Immunol. 2011; 128:125-131. e122. [PubMed: 21601913] Refs [30,31] suggest that incorporation of baked milk or egg products into the diets of milk- or egg-allergic subjects, respectively, can be immunomodulatory and hasten food allergy resolution.

31. Leonard SA, Sampson HA, Sicherer SH, Noone S, Moshier EL, Godbold J, Nowak-Wegrzyn A. Dietary baked egg accelerates resolution of egg allergy in children. J Allergy Clin Immunol. 2012; 130:473-480. e471. [PubMed: 22846751]

32. Bannon GA, Cockrell G, Connaughton C, West CM, Helm R, Stanley JS, King N, Rabjohn P, Sampson HA, Burks AW. Engineering, characterization and in vitro efficacy of the major peanut allergens for use in immunotherapy. Int Arch Allergy Immunol. 2001; 124:70-72. [PubMed: 11306930]

33. Li XM, Srivastava K, Grishin A, Huang CK, Schofield B, Burks W, Sampson HA. Persistent protective effect of heat-killed Escherichia coli producing "engineered" recombinant peanut proteins in a murine model of peanut allergy. J Allergy Clin Immunol. 2003; 112:159-167. [PubMed: 12847493]

34. Wood RA, Sicherer SH, Burks AW, Grishin A, Henning AK, Lindblad R, Stablein D, Sampson HA. A phase 1 study of heat/phenol-killed, E. coli-encapsulated, recombinant modified peanut proteins Ara h 1, Ara h 2, and Ara h 3 (EMP-123) for the treatment of peanut allergy. Allergy. 2013; 68:803-808. [PubMed: 23621498]

35. Leung DY, Sampson HA, Yunginger JW, Burks AW Jr, Schneider LC, Wortel CH, Davis FM, Hyun JD, Shanahan WR Jr. Effect of anti-IgE therapy in patients with peanut allergy. N Engl J Med. 2003; 348:986-993. [PubMed: 12637608]

36. Sampson HA, Leung DY, Burks AW, Lack G, Bahna SL, Jones SM, Wong DA. A phase II, randomized, doubleblind, parallelgroup, placebocontrolled oral food challenge trial of Xolair (omalizumab) in peanut allergy. J Allergy Clin Immunol. 2011; 127:1309-1310. e1301. [PubMed: 21397314]

37. Nadeau KC, Schneider LC, Hoyte L, Borras I, Umetsu DT. Rapid oral desensitization in combination with omalizumab therapy in patients with cow's milk allergy. J Allergy Clin 
Immunol. 2011; 127:1622-1624. [PubMed: 21546071] This brief report provides evidence that adjunct treatment with omalizumab can increase the safety and efficacy of milk OIT.

38. Srivastava KD, Kattan JD, Zou ZM, Li JH, Zhang L, Wallenstein S, Goldfarb J, Sampson HA, Li XM. The Chinese herbal medicine formula FAHF-2 completely blocks anaphylactic reactions in a murine model of peanut allergy. J Allergy Clin Immunol. 2005; 115:171-178. [PubMed: 15637565]

39. Song Y, Qu C, Srivastava K, Yang N, Busse P, Zhao W, Li XM. Food allergy herbal formula 2 protection against peanut anaphylactic reaction is via inhibition of mast cells and basophils. $\mathbf{J}$ Allergy Clin Immunol. 2010; 126:1208-1217. e1203. [PubMed: 21134573]

40. Wang J, Patil SP, Yang N, Ko J, Lee J, Noone S, Sampson HA, Li XM. Safety, tolerability, and immunologic effects of a food allergy herbal formula in food allergic individuals: a randomized, double-blinded, placebo-controlled, dose escalation, phase 1 study. Ann Allergy Asthma Immunol. 2010; 105:75-84. [PubMed: 20642207]

41. Patil SP, Wang J, Song Y, Noone S, Yang N, Wallenstein S, Sampson HA, Li XM. Clinical safety of Food Allergy Herbal Formula-2 (FAHF-2) and inhibitory effect on basophils from patients with food allergy: extended phase I study. J Allergy Clin Immunol. 2011; 128:1259-1265. e1252. [PubMed: 21794906]

42. Beeh KM, Kanniess F, Wagner F, Schilder C, Naudts I, Hammann-Haenni A, Willers J, Stocker H, Mueller P, Bachmann MF, et al. The novel TLR-9 agonist QbG10 shows clinical efficacy in persistent allergic asthma. J Allergy Clin Immunol. 2013; 131:866-874. [PubMed: 23384679]

43. Jouvin MH, Kinet JP. Trichuris suis ova: testing a helminthbased therapy as an extension of the hygiene hypothesis. J Allergy Clin Immunol. 2012; 130:3-10. [PubMed: 22742834]

44. Pelaia G, Vatrella A, Maselli R. The potential of biologics for the treatment of asthma. Nat Rev Drug Discov. 2012; 11:958-972. [PubMed: 23197041]

45. Dupont C, Kalach N, Soulaines P, Legoue-Morillon S, Piloquet H, Benhamou PH. Cow's milk epicutaneous immunotherapy in children: a pilot trial of safety, acceptability, and impact on allergic reactivity. J Allergy Clin Immunol. 2010; 125:1165-1167. [PubMed: 20451043]

46. De Souza Reboucas J, Esparza I, Ferrer M, Sanz ML, Irache JM, Gamazo C. Nanoparticulate adjuvants and delivery systems for allergen immunotherapy. J Biomed Biotechnol. 2012; 2012:474605. [PubMed: 22496608]

47. Reboucas Jde S, Irache JM, Camacho AI, Esparza I, Del Pozo V, Sanz ML, Ferrer M, Gamazo C. Development of poly(anhydride) nanoparticles loaded with peanut proteins: the influence of preparation method on the immunogenic properties. Eur J Pharm Biopharm. 2012; 82:241-249. [PubMed: 22782031]

48. Pajno GB, Caminiti L, Ruggeri P, De Luca R, Vita D, La Rosa M, Passalacqua G. Oral immunotherapy for cow's milk allergy with a weekly up-dosing regimen: a randomized singleblind controlled study. Ann Allergy Asthma Immunol. 2010; 105:376-381. [PubMed: 21055664] 


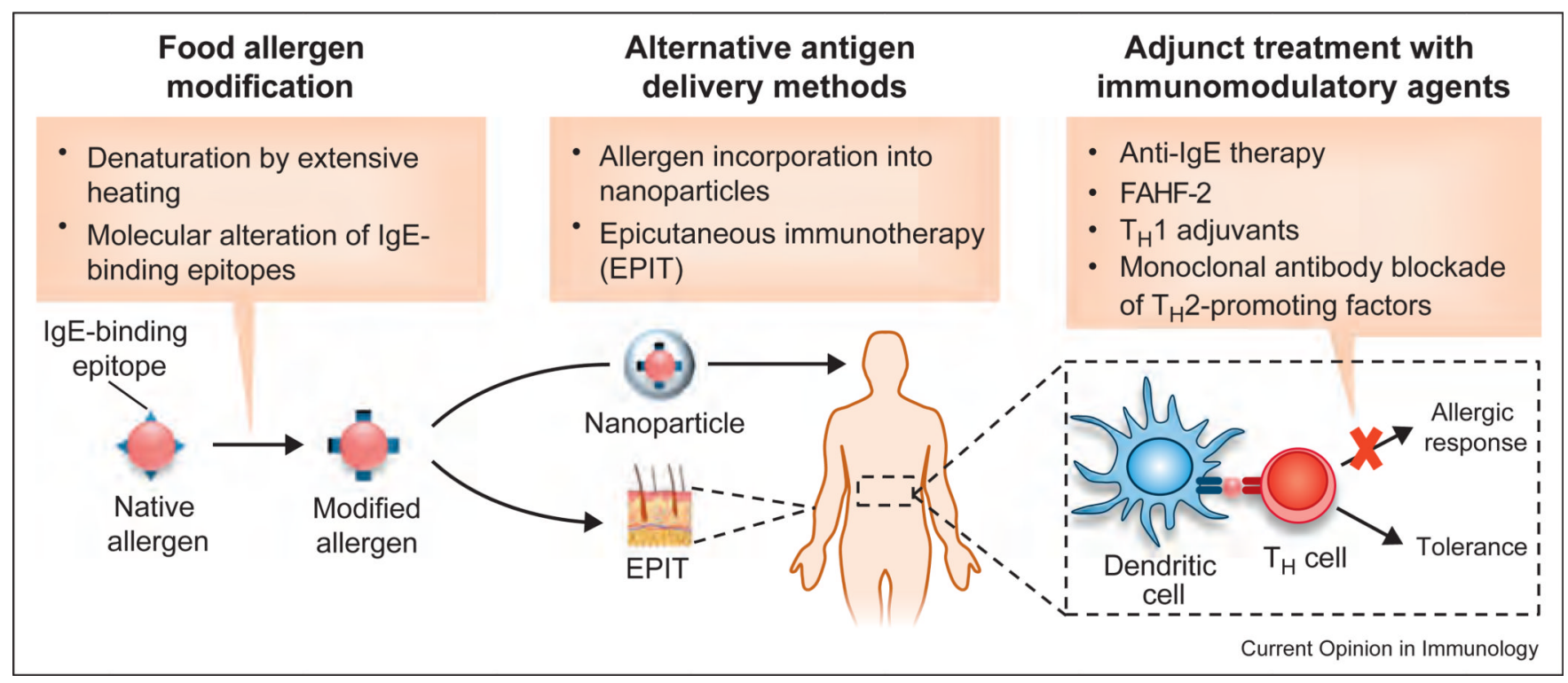

Figure 1.

Strategies for improving food immunotherapy. Modification of food allergens to reduce recognition by $\operatorname{IgE}$ can be accomplished by extensive heating or molecular alteration of immunodominant epitopes. Incorporation of food allergens into nanoparticles or epicutaneous delivery of antigen could improve immunotherapy efficacy while reducing treatment-associated adverse reactions. Finally, adjunct use of immunomodulatory agents may prevent allergic responses mediated by allergen-specific $\mathrm{T}$ helper $\left(\mathrm{T}_{\mathrm{H}}\right)$ cells, and promote tolerance through induction of $\mathrm{T}$ cell anergy or development of regulatory $\mathrm{T}$ cells. 


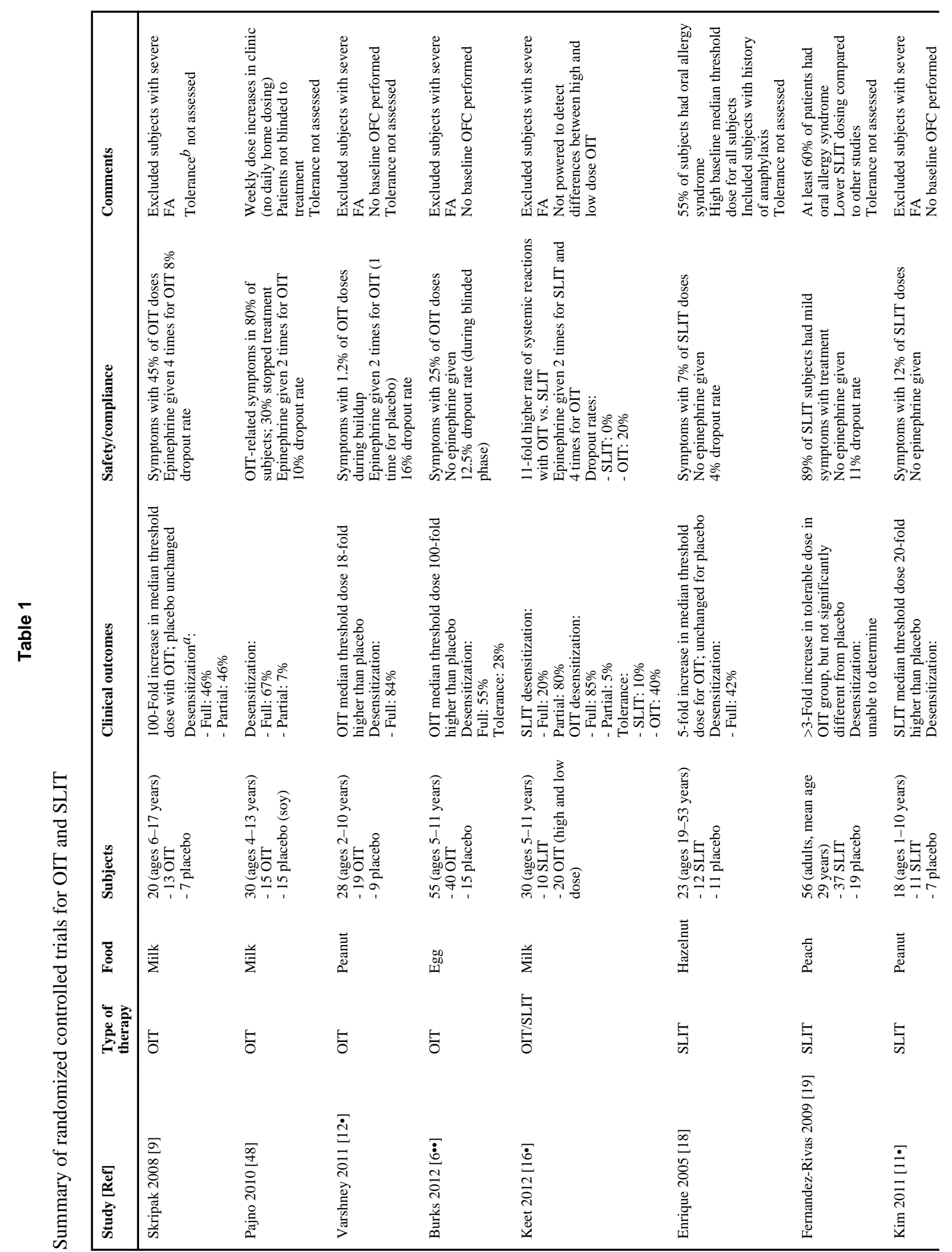

Curr Opin Immunol. Author manuscript; available in PMC 2014 February 26. 


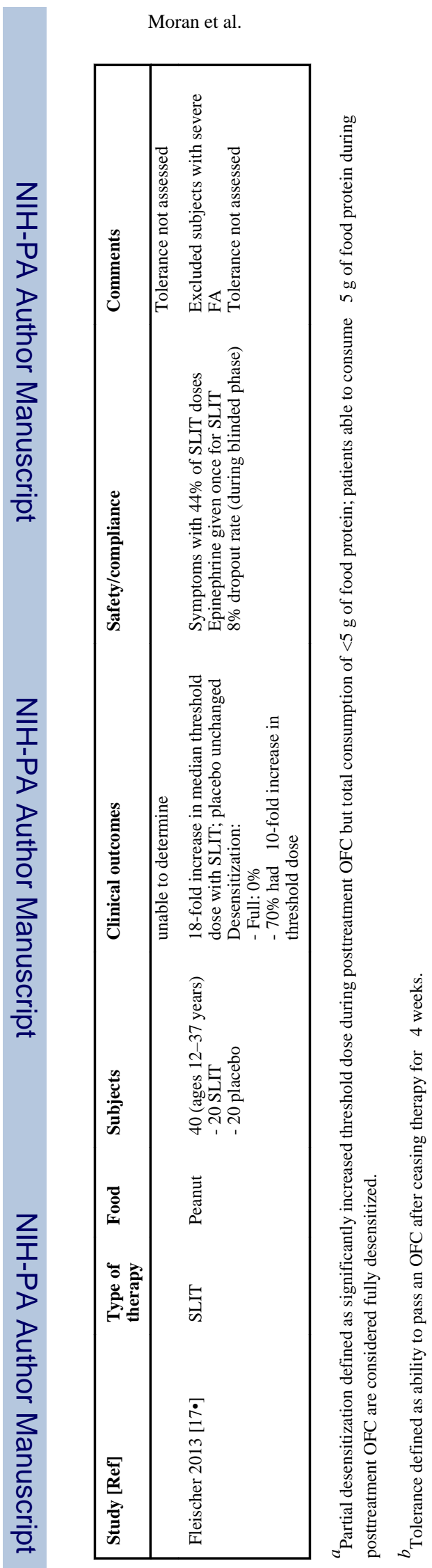

Curr Opin Immunol. Author manuscript; available in PMC 2014 February 26. 